\title{
Assessment of Knowledge and Attitude toward Antibiotic Use and Resistance among Students of International University of Africa, Medical complex, Sudan
}

\author{
Lawan Sa'adatu Sunusi, Mousnad Mohamed Awad*, Njelekela Makinga Hassan and Chiroma Abubakar Isa \\ Faculty of Pharmacy, International University of Africa (IUA), Sudan²Department of Pharmacology, National Research Centre, Cairo
}

\begin{abstract}
Objective: This study aimed to explore the attitude of students in IUA medical complex on antibiotic usage and knowledge on antibiotic resistance and relate these to gender, age and the cost of health-care.

Material and Method: A total of 311 questionnaires were randomly distributed to the students of the different faculties in IUA medical complex that are in their 3rd, 4 th, or 5 th years of studies and 306 questionnaires out of $n=311$ were returned and were used to assess the knowledge and attitude of the participants. These variables were assessed using a ten-point scale, whose responses ranged from "always" to "never", "yes" to "I don't know" and level of knowledge on antibiotics was assessed using a nine-point scale with responses that ranged from "true" to "I don't know". The data were analyzed using simple descriptive statistics and wherever required chi-square test was used to determine significant differences.
\end{abstract}

Results: The response rate to the questionnaire was about $98 \%$. The participants had shown $44.44 \%, 34.3 \%, 20.3 \%$ and $1 \%$ good, poor, very good and excellent knowledge on resistance respectively. However, only $24.8 \%$ had a good attitude, $60.1 \%$ had average attitude and $15 \%$ had a bad attitude.

Conclusion: The students attitude is average despite having good knowledge and students characteristics like age, gender and health care cost have negligible impact on the students knowledge and attitude.

\begin{abstract}
Abbreviations: TB: Tuberculosis; WHO: World Health Organisation; AMR: antimicrobial resistance; AMU: antimicrobial use; FMOH: Federal Ministry of Health; MOAR: Ministry of Agriculture; IUA: International University of Africa.
\end{abstract}

\section{Introduction}

Resistance to antibiotics is significantly increasing in almost all population. This increase can be attributed to lack of knowledge on the issue of antibiotic resistance and inappropriate attitudes towards their usage like self-medication. This work assessed the relationship of student's knowledge of antibiotic resistance and their attitudes towards antibiotic usage. Also at the same time determine the level of the students' knowledge of antibiotic. Which will aid in reducing the significant increase in the rate of resistance as these students will directly or indirectly have some role to play on the rational use of these drugs. The medical complex of the International University of Africa encompasses five faculties which include: faculty of medicine, faculty of pharmacy, faculty of dentistry, faculty of nursing and faculty of medical laboratory sciences.

To start, antibiotics, also known as antibacterial, are medications that destroy or slow down the growth of bacteria. They include a range of powerful drugs and are used to treat diseases caused by bacteria. Antibiotics cannot treat viral infections, such as cold, flu, and most coughs. Antibiotic resistance occurs when bacteria change in some way that reduces or eliminates the effectiveness of drugs, chemicals, or other agents designed to cure or prevent infections. The bacteria survive and continue to multiply causing more harm. Frequent and inappropriate use of antibiotics can cause bacteria or other microbes to change so antibiotics don't work against them. Because of antibiotic overuse, certain bacteria have become resistant to even the most powerful antibiotics available today.

Antibiotic resistance is rising to dangerously high levels in all parts of the world. New resistance mechanisms are emerging and spreading globally, threatening our ability to treat common infectious diseases. A growing list of infections-such as pneumonia, tuberculosis (TB), blood poisoning, gonorrhoea, and food borne diseases-are becoming harder, and sometimes impossible, to treat as antibiotics become less effective. Where antibiotics can be bought for human or animal use without a prescription, the emergence and spread of resistance is made worse. Similarly, in countries without standard treatment guidelines, antibiotics are often over-prescribed by health workers and veterinarians and over-used by the public. Without urgent action, we are heading for a post-antibiotic era, in which common infections and minor injuries can once again kill [1]

Antibiotic resistance leads to higher medical costs, prolonged hospital stays, and increased mortality. The world urgently needs to change the way it prescribes and uses antibiotics. Even if new medicines

${ }^{\star}$ Correspondence to: Mousnad Mohamed Awad, Faculty of Pharmacy, International University of Africa (IUA), Khartoum, Sudan, E-Mail: m_abdalaziz@yahoo.com

Key words: antibiotic resistance, antibiotic usage, knowledge, attitude, Sudan

Received: October 02, 2019; Accepted: October 28, 2019; Published: November 01,2019 
are developed, without behaviour change, antibiotic resistance will remain a major threat. Tackling antibiotic resistance is a high priority for WHO. A global action plan on antimicrobial resistance, including antibiotic resistance, was endorsed at the World Health Assembly in May 2015. The global action plan aims to ensure the prevention and treatment of infectious diseases with safe and effective medicines. The "Global action plan on antimicrobial resistance" has 5 strategic objectives one of which is: to improve awareness and understanding of antimicrobial resistance [2].

Numerous studies have reported improper antibiotic use among students both of medical and non-medical colleges with self-medication and adequate lack of knowledge of antibacterial agents (indications, compliance to dosage regimen, specificity of agents to infective organism) [3-5]. While another study concluded that there is a gap between theoretical input and clinical practices, what is being learn by the student differs from what is being practice or they don't always seem to apply the theoretical knowledge when it comes to real-life situations. A more practical method should be used when educating the students particularly the knowledge of antibiotic use [6].

About antibiotic resistance in Sudan, a in 2007 study establishes high prevalence of self-medication with antibiotics and antimalarial among undergraduate university students in Khartoum state and recently an article in the journal of advanced microbiology stated that as of 2016 the current situation of antimicrobial resistance (AMR) in Sudan is that; the antimicrobial use (AMU) is not regulated and antimicrobial agents can be easily obtained over the counter from pharmacies, general stores and market stalls [7]. No maps of antimicrobial sales and distribution pathways available now, furthermore, no specific guidelines on AMU [8]. Also there are not many studies on antibiotic use or resistance and most of the available studies are carried by individual researchers because of personal interests and for academic awards. Therefore, these type of studies in both human and agricultural sector are scarce and fragmentary and there is no antimicrobial surveillance on country wise. Sudan population is approaching 40 million and livestock is approximated to be 107 million (FMOH 2014; MOAR 2016).

In the setting of this research a small a few to none previous studies on this topic has been carried out and none of its kind in the university but there is some background information on general status of antibiotic resistance in Sudan as stated in a research carried out in 2016 on the current situation of bacterial resistance to antibiotics in Sudan established that E. coli, Klebsiella spp, Proteus spp, Pseudomonas aeruginosa, Sphylococcus aureus, Mycobacterium tuberculosis and Salmonella enteriditis were the most commonly encountered organisms in samples of blood, urine, stool and sputum obtained for the study and these organisms were found to be highly resistant to chloramphenicol, penicillin, sulbactam, cefotaxime, amoxicillin, erythromycin, tetracycline, nitrofurantaoin, nalidixic acid, colistin sulphate, streptomycin, vancomycin, imipenem, amikacin and tobramycin which can be noticed to be almost all the available and effective antibiotic agents thus the prevalence of resistance and the need to find solutions to the increasing problem [8].

The aim of this study was to evaluate the knowledge of antibiotic resistance and the attitude of antibiotic usage among students in IUA medical complex from June to July 2019.

\section{Materials and Method}

A cross-sectional, questionnaire-based survey conducted between June 2019 and July 2019. The study was conducted at the IUA Medical Complex Faculties.
The Study population IUA is a public university in Khartoum, Sudan. It is a member of the federation of universities of the Islamic world. The university has 64 Faculties which include Medicine, Dentistry, Pharmacy, Nursing and Medical laboratory which are the focus of this work. The students come from 84 countries including Sudan and other African countries and some Asian countries.

This study has explored the knowledge of 3rd, 4th and 5th year students in IUA medical complex campus consisting of 667 students in faculty of medicine, 252 students in faculty of pharmacy, 351 in faculty of dentistry, 143 in faculty of nursing and 202 in medical laboratory sciences faculty on antibiotic resistance and also determined their attitudes and medication habits towards the usage of these antibiotics. These students get health-care services mainly from the university primary care centre, which has 12 doctors, 3 dentists, 8 nurses and 7 medical laboratory technicians. Only Students of 3rd, 4th and 5th levels of faculties of medicine, pharmacy and dentistry and 3rd and 4th levels of faculties of nursing and medical lab science were included in this study.

The study excluded all students of IUA medical faculties that are in their 1st and 2nd year of study.

The Sample size of 311 students was calculated by excel sheet and also by Roasoft sample size calculator. And a simple random sampling method was employed in this work.

Data were collected by administering questionnaires. The questionnaires were validated by lecturers from the department of pharmacy practice, IUA and was pretested on a sample of students that were randomly selected from the various medical complex faculties, and an explanation was done to any question which was not clear to them in order to evaluate the clarity of the questionnaire and these where not used in the main study.

Data management and statistical analysis

Data analysis was done using Statistical Package of Social Sciences (SPSS) version.20

\section{Descriptive statistics: frequency and percentage}

Inferential statistics: chi-square test

\section{Results}

\section{Demographics characteristics}

The response rate to the questionnaire was about 98\% (306 respondents out of 311) Majority of the participants' age ranges between $21-24$ years $(71.9 \%)$ and only $14.1 \%$ the participants are aged 25 years and above and another $14.1 \%$ age between $17-20$ years.70.9\% were male students and $29.1 \%$ female students.

The 3rd year students (38.6\%) have largest number of respondents while the 5th year students have the lowest number (24.5\%)The participants that are in 4th year are (36.9\%) Most of the participants are from the faculty of pharmacy (30.1\%), $27.1 \%$ are students from the faculty of medicine, $19.3 \%$ from faculty of dentistry while the faculties of nursing and medical lab sciences have the smallest number of participants $(11.8 \%)$ and faculty of medicine.

The participants cost of health-care was gauged based on the type of clinics they visited and how they pay their medical bills. And it was found out that the participants visit private clinics (56.2\%) more than public clinics $(43.8 \%)$ and $58.8 \%$ of the participants are not covered by insurance they paid the medical bills by self-payment while $28.4 \%$ 
of the participants' medical bills are partially covered by insurance and only $12.7 \%$ of the participants have their medical bills completely covered by insurance.

\section{Assessment of participants' knowledge of antibiotics}

Table 1A shows the frequency and distribution of participants' responses to questions regarding antibiotics. This can be used to determine their background knowledge of this class of drugs (Figure 1).

In accordance with the grading scale devised only $2 \%$ of the participants were found to have excellent knowledge and 34.3\% to have poor knowledge, the rest lie between very good (23.5) and good with good knowledge level having the highest percentage (40.2\%) see Table $1 \mathrm{~B}$.

\section{Assessment of participants' knowledge of antibiotics resistance}

As it can be seen in Table 2A and Table 2B, (44.4\%) of the participants have good knowledge of antibiotic resistance about( $34.3 \%$ ) have poor knowledge which is a huge number considering the fact that the study group are students in medical and health-related sciences fields and only (1\%) have excellent knowledge on antibiotic resistance.

After running a chi-square test the p-value obtained shows that the participants' knowledge of antibiotic resistance and their age groups ( $\mathrm{p}$-value $=.654$ ) are independent, there was no significant association or correlation between the two so also the participants' cost of health-care which was gauged using type of clinics the participants obtained their health-care services from ( $\mathrm{p}$-value=.193) and their type of medical bill payment ( $\mathrm{p}$-value $=.417$ ) On the other hand, a significant relationship was observed between gender and knowledge on antibiotic resistance in these participants. ( $\mathrm{p}$-value $=0.34$ ) (Figure 2).

\section{Assessment of participants' attitude regarding the usage of antibiotics}

As seen in Table $3 \mathrm{~A}$ only $2.3 \%$ scored 10 out of 10 on attitude and the highest number of participants scored 7 out of $10(22.2 \%)$ generally, the scores obtained by the participants on the test of attitude of antibiotic usage was seen to be less diverse and only (0.3\%) scored less than 3 out of 10 . Table $3 \mathrm{~B}$ shows the result according to the attitude grading scale used in this work, $(60.1 \%)$ have average attitude, $(24.8 \%)$ have good attitude and (15\%) were seen to have bad attitude toward antibiotic usage [9].

When determining the whether age, gender and cost of health care have effect on the participants' attitude it was found that the attitude regarding antibiotic usage is independent of age range, there was no significant correlation ( $\mathrm{p}$-value $=.069$ ) between the two in these participants. No relationship between gender of participants and their attitude was ( $\mathrm{p}$-value $=.513$ ) Attitude regarding antibiotic usage also independent of the method of participants' medical bill payment ( $p$-value=.909) and lastly, no relationship exists between attitude of

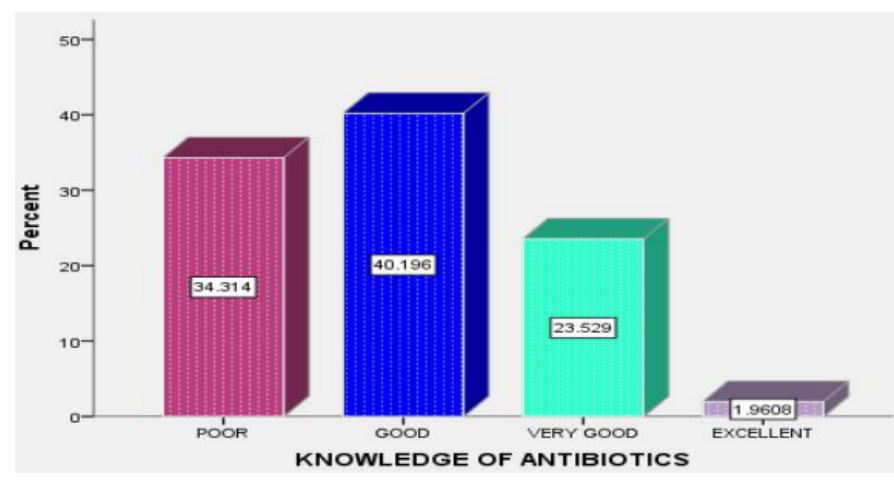

Figure 1. The chart illustrating the grading of the participants level of knowledge of antibiotics

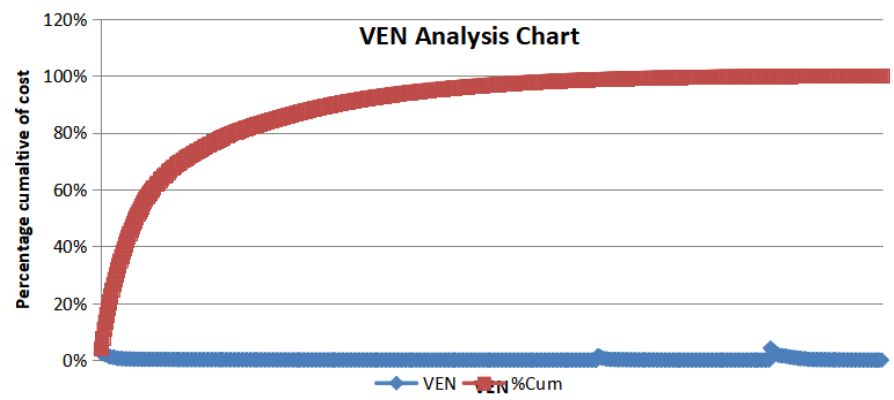

Figure 2. The chart illustrating the grading of the participants level of knowledge of antibiotics resistance

Table 1A. Frequency and distribution of participants according to the responses to questions on antibiotics

\begin{tabular}{|c|c|c|c|c|}
\hline \# & Statement & True N(\%) & False $N(\%)$ & Donot know $(\%)$ \\
\hline $\mathrm{i}$ & Antibiotics are safe drugs, hence can be commonly used medications & $188(62.5 \%)$ & $103(34.2 \%)$ & $10(3.3 \%)$ \\
\hline ii & Broad spectrum antibiotics are more preferred for the treatment of bacterial infection & $208(69.6 \%)$ & $63(21.1 \%)$ & $28(9.3 \%)$ \\
\hline iii & Antibiotics are not effective drugs for the treatment of fever & $156(53.1 \%)$ & $115(39.1 \%)$ & $23(7.8 \%)$ \\
\hline iv & There is no difference between coamoxiclav (Amoclan) and Amoxicillin & $57(19.3 \%)$ & $164(55.4 \%)$ & $75(25.3 \%)$ \\
\hline $\mathrm{v}$ & Antibiotics should only be used when prescribed & $256(85.3 \%)$ & $35(11.7 \%)$ & $9(3.0 \%)$ \\
\hline vi & Antibiotics are not supposed to kill all bacteria in the body & $256(85.3 \%)$ & $35(11.7 \%)$ & $9(3.0 \%)$ \\
\hline vii & The body can usually fight mild infections on its own without antibiotics & $254(84.5 \%)$ & $35(10.9 \%)$ & $13(4.6 \%)$ \\
\hline viii & $\begin{array}{l}\text { Susceptibility tests helps to determine the likelihood that a particular antibiotic will be effective in treatment of a } \\
\text { certain bacterial infection. }\end{array}$ & $227(74.9 \%)$ & $22(7.3 \%)$ & $57(17.8 \%)$ \\
\hline ix & Antibiotics treat infections from fungi, virus and bacteria & $121(42.0 \%)$ & $154(52.2 \%)$ & $20(5.8 \%)$ \\
\hline
\end{tabular}

Table 1B. Frequency and distribution of grading of the participants 'according to knowledge of antibiotic

\begin{tabular}{|c|c|c|}
\hline Knowledge Level & Frequency & Percentage \\
\hline Poor & 105 & $34.3 \%$ \\
\hline Good & 123 & $40.2 \%$ \\
\hline Very good & 72 & $23.5 \%$ \\
\hline Excellent & 6 & $2 \%$ \\
\hline Total & 306 & 100 \\
\hline
\end{tabular}


Sunusi LS (2019) Assessment of Knowledge and Attitude toward Antibiotic Use and Resistance among Students of International University of Africa, Medical complex, Sudan

Table 2A. Frequency and percentage of the responses of participants to questions on antibiotic resistance

\begin{tabular}{|c|c|c|c|c|}
\hline & Statement & Yes $\mathbf{N}(\%)$ & No $N(\%)$ & Do not know N(\%) \\
\hline i & Bacteria can become resistant to antibiotics. & $285(95 \%)$ & $9(3 \%)$ & $6(2 \%)$ \\
\hline ii & People can become resistant to antibiotics. & $189(63.2 \%)$ & $86(28.8 \%)$ & $24(8.0 \%)$ \\
\hline iii & The more antibiotics we use in society, the higher is the risk that resistance develops and spreads. & $249(82.2 \%)$ & $27(8.9 \%)$ & $27(8.9 \%)$ \\
\hline iv & Non-compliance does not contribute to the development of antibiotics resistance. & $71(24.0 \%)$ & $140(47.3 \%)$ & $85(28.7 \%)$ \\
\hline $\mathrm{v}$ & Resistance can spread from animals to humans. & $110(37.4 \%)$ & $98(33.3 \%)$ & $86(29.3 \%)$ \\
\hline vi & Resistance can spread from person to person. & $125(41.7 \%)$ & $107(35.7 \%)$ & $68(22.6 \%)$ \\
\hline vii & Today, antibiotics resistance is not a big problem in the world. & $68(22.7 \%)$ & $202(67.6 \%)$ & $29(9.7 \%)$ \\
\hline viii & Taking antibiotics correctly may reduce the risk of antibiotic resistance & $252(84.8 \%)$ & $30(10.1 \%)$ & $15(5.1 \%)$ \\
\hline ix & Antibiotics should be stopped immediately when the patient is clinically improved to reduce the risk of resistance & $144(48 \%)$ & $127(42.3 \%)$ & $29(9.7 \%)$ \\
\hline $\mathrm{x}$ & $\begin{array}{l}\text { As a student in the medical line and also a member of the society do you think you have a role to play in decreasing } \\
\text { the prevalence of antibiotic resistance? }\end{array}$ & $248(83.2 \%)$ & $22(7.4 \%)$ & $28(9.4 \%)$ \\
\hline
\end{tabular}

Table 2B. Frequency and distribution of participants grading on the level of knowledge of antibiotic resistance

\begin{tabular}{|c|c|c|}
\hline Knowledge Level & Frequency & Per cent \\
\hline Poor & 105 & $34.3 \%$ \\
\hline Good & 136 & $44.4 \%$ \\
\hline Very Good & 62 & $20.3 \%$ \\
\hline Excellent & 3 & $1 \%$ \\
\hline Total & 306 & $100 \%$ \\
\hline
\end{tabular}

Table 3A. Frequency and distribution of responses of participants' to questions on attitude regarding the usage of antibiotics

\begin{tabular}{|c|c|c|c|c|}
\hline & Statement & Always N(\%) & Sometime N(\%) & Never $\mathbf{N}(\%)$ \\
\hline $\mathrm{i}$ & Do you always get a prescription before starting antibiotics? & $129(43.1 \%)$ & $157(52.5 \%)$ & $13(4.4 \%)$ \\
\hline ii & Do you stop taking the prescribed antibiotics after your symptoms improved? & $96(32.7 \%)$ & $121(41.1 \%)$ & $77(26.2 \%)$ \\
\hline iii & Do you complete the course of the prescribed antibiotic treatment? & $129(43.6 \%)$ & $123(41.6 \%)$ & $44(14.8 \%)$ \\
\hline iv & Do you take the correct dose of your antibiotics at the right time for the full duration? & $153(51.5 \%)$ & $135(45.5 \%)$ & $9(3.0 \%)$ \\
\hline $\mathrm{v}$ & In case of missed dose, do you take it as soon as possible when you remember before the time of next dose? & $137(46.1 \%)$ & $110(37.1 \%)$ & $50(16.8 \%)$ \\
\hline vi & Do you save the remaining antibiotics for next time you get sick? & $72(24.1 \%)$ & $109(36.5 \%)$ & $118(39.4 \%)$ \\
\hline vii & Do you give leftover medication to friends or family if they get sick? & $46(15.7 \%)$ & $129(44.0 \%)$ & $118(40.3 \%)$ \\
\hline viii & Do you prefer taking an antibiotic when you have cough or sore throat? & $70(20.5 \%)$ & $103(30.2 \%)$ & $168(49.3 \%)$ \\
\hline ix & $\begin{array}{l}\text { You buy the same antibiotics if you are sick and they helped you get better when you had the same symptoms } \\
\text { before. }\end{array}$ & $98(32.1 \%)$ & $139(45.4 \%)$ & $69(22.5 \%)$ \\
\hline $\mathrm{x}$ & Do you check the expiry date of the antibiotic before using it? & $210(69.5 \%)$ & $64(21.2 \%)$ & $28(9.3 \%)$ \\
\hline
\end{tabular}

Table 3B. Frequency and distribution of participants' grading on attitude regarding antibiotic usage [9]

\begin{tabular}{|c|c|c|}
\hline Attitude Level & Frequency & Percent \\
\hline Bad Attitude & 46 & $15 \%$ \\
\hline Average Attitude & 184 & $60.1 \%$ \\
\hline Good Attitude & 76 & $24.8 \%$ \\
\hline Total & 306 & $100 \%$ \\
\hline
\end{tabular}

participants regarding antibiotic usage and the type of health-care provider they obtain their health-care services from. (P-value=.439) (Figure 3).

\section{Relationship between knowledge on antibiotics resistance and attitude of antibiotic usage}

By running a chi-square test and taking significance level $=.05$ It can be concluded that a relationship exists between knowledge of antibiotic resistance and the attitude of participants regarding the usage of antibiotics (P-value $=.000)$ (Table 4).

Solutions to tackle the increasing rate of antibiotic resistance: Most of the participants see that dispensing antibiotics only with prescription to be the most effective solution to antibiotic resistance (25.9\%). Also a large number consider more enlightenment on antibiotic resistance to be an effective solution (24.8\%) and about (4\%) of the participants feel there are more solutions to tackle antibiotic resistance apart from the ones listed in Table 5 (Figure 4).

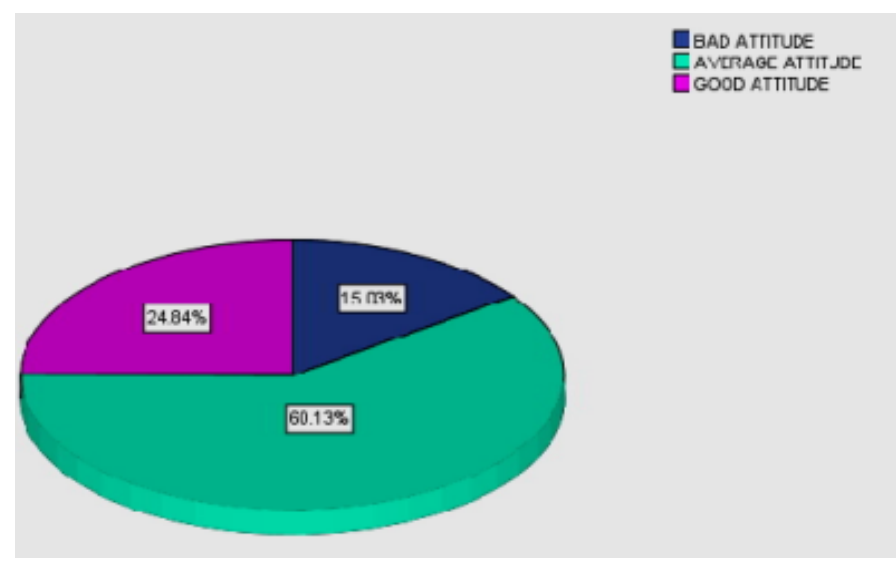

Figure 3. The pie chart illustrating the participants' grading on attitude regarding antibiotic usage 


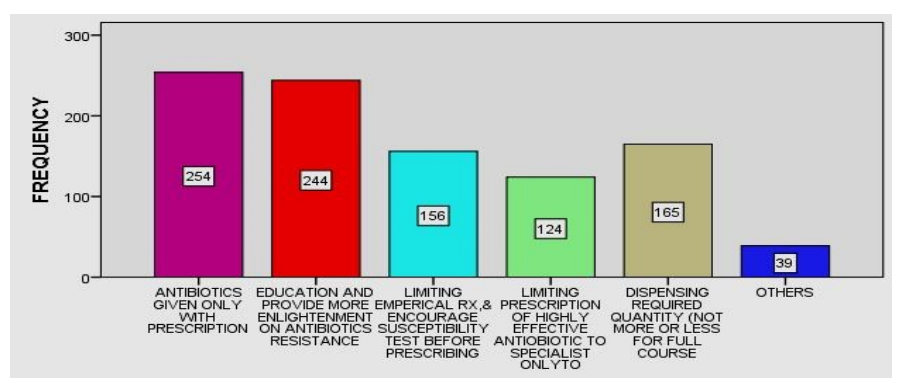

Figure 4. The chart illustrating the participants' suggested solutions on tackling antibiotic resistance

Table 4. Correlation between participants' knowledge on antibiotic resistance and attitude regarding antibiotic usage

\begin{tabular}{|c|c|c|c|c|c|}
\hline \multirow{2}{*}{} & \multicolumn{3}{|c|}{ Attitude Towards Antibiotic Usage } & Total \\
\cline { 3 - 6 } & & Bad Attitude & $\begin{array}{c}\text { Average } \\
\text { Attitude }\end{array}$ & Good Attitude & \\
\hline \multirow{3}{*}{$\begin{array}{c}\text { Knowledge } \\
\text { of Antibiotic } \\
\text { Resistance }\end{array}$} & Poor & 25 & 67 & 13 & 105 \\
\cline { 2 - 6 } & Gery Good & 18 & 83 & 35 & 136 \\
\cline { 2 - 6 } & Excellent & 0 & 32 & 27 & 62 \\
\hline Total & & 46 & 184 & 76 & 306 \\
\hline
\end{tabular}

Note: Chi square $=26.864^{\mathrm{a}} ; \mathrm{p}$-value $=0.000$

Table 5. Frequency and distribution of effective solutions to antibiotic resistance

\begin{tabular}{|l|c|c|}
\hline Solutions & Frequency & Percentage \\
\hline $\begin{array}{l}\text { Ensure that antibiotics are given only with prescription } \\
\text { More education and enlightenment on antibiotic resistance } \\
\text { and providing more information on antibiotics. }\end{array}$ & 254 & 25.9 \\
\hline $\begin{array}{l}\text { Limiting empiric treatment and encouraging susceptibility } \\
\text { tests before prescribing antibiotic }\end{array}$ & 156 & 15.9 \\
\hline $\begin{array}{l}\text { Limiting the prescription of highly effective antibiotics } \\
\text { (those that do not develop resistance) to specialist only }\end{array}$ & 124 & 12.6 \\
\hline $\begin{array}{l}\text { Dispensing the required quantity of the antibiotics not less } \\
\text { or more than the quantity required for the full course of } \\
\text { treatment }\end{array}$ & 165 & 16.8 \\
\hline \begin{tabular}{l} 
Others \\
\hline Total
\end{tabular} & 39 & 4 \\
\hline
\end{tabular}

\section{Discussion}

From the result we can obtain the answer to the question "what is the level of students' knowledge on antibiotic resistance and their attitude of antibiotic usage and how does the students' age, gender and cost of health-care related to the knowledge and attitude?" and also test the hypothesis that "The students in IUA medical complex generally have good knowledge of resistance and good attitude of antibiotic usage, also the students' level of knowledge should determine their attitude." These can be seen in the main findings which are summarized into the following points:

\section{Knowledge of antibiotics}

The level of the students' knowledge of antibiotics is generally "good" as (40.2\%) of the participants scores are within that grade, a considerable number (34.5\%) of students' scores shows they have "poor" knowledge and the smallest number only (2\%) have "excellent" knowledge which is unexpected in this group of individuals due to type of training they are receiving.

\section{Knowledge of antibiotic resistance}

The students' knowledge of resistance was also "good" (44.4\% of the participants) and the students' score grade pattern on this section is similar to that of the knowledge of antibiotics. Thereby, showing that knowledge of antibiotics and knowledge of resistance go hand in hand in the subjects used in this study. The gender of the students was seen to be related to the knowledge of antibiotic resistance as the p-value obtained after running a chi-square test is less than the significance level taken (0.050).

In contrary, the age and cost of health-care was not associated with the level of knowledge on resistance. Due to the obtained p-values being greater than 0.05 . So, no significant relationship between the students' knowledge with their age and cost of health-care which was determined by the method of medical bill payment and the type of health-care provider.

\section{Attitude regarding antibiotics usage}

The student attitude in this section was found to be "average" meaning most of them (60.1\%) score between 5-7 points on the section that tests the attitude. This means that these students often try to do the right thing regarding antibiotic use but not all the time i.e. even with the knowledge they do not always have good attitude towards antibiotic usage, they have an idea on the issue but seldom do what is right according to their knowledge. This can be seen to be not in cohesion with the hypothesis of this work.

The p-values of the correlation studies shows that the attitude is not associated with the students' age, gender and cost of health-care. The attitude is independent of the above students' characteristics which is understandable because the average attitude has the largest number of participants which is irrespective of their age, gender and healthcare cost, so it is expected that the attitude is not related to the above characteristics.

The students' attitude towards the usage of antibiotics was correlated to their knowledge on antibiotic resistance that is the level of knowledge can determine the attitude and vice-versa. As it can be noticed from the result (poor knowledge, bad attitude $=25$ ) and (poor knowledge, good attitude $=13$ ) the trend continues in this way throughout.

\section{Solutions to tackle antibiotic resistance}

It was ascertained from the responses of the students that they think antibiotics resistance can be tackled by the various ways suggested by in this study and also a few number of the students even added more to the list of solutions. $25.9 \%$ say that giving antibiotic only with prescription is the solution. $24.8 \%$ suggest education and enlightenment. $16.8 \%$ say dispensing only the required quantity for the treatment is an also a means of tackling the resistance. $15.9 \%$ are of the opinion that limiting empirical treatment. $12.6 \%$ feeling restriction on prescription of highly effective antibiotic should be enforced on non-specialist. $4 \%$ think there are more ways to tackle resistance apart from the ones above.

\section{Conclusion}

Despite having good knowledge of antibiotics and also good knowledge on antibiotic resistance the majority of these students have average attitude regarding the usage of antibiotic which is not enough in a population of students who are studying health related fields. Furthermore, they are in their clinical years or even some of them are about to graduate and go into the health-care system. Many will look up to these students or ask them for advice on matters regarding health, antibiotic resistance inclusive so it is required that they have a good attitude and very good knowledge on this aspect if not excellent attitude at least. 


\section{Implications and study recommendations}

As it was pointed out above, there is a need for more education and enlightenment of these students on the importance of antibiotic resistance.

Workshops on appropriate behavior towards the use of antibiotic can help the students merge what they know and what should be done together i.e put their knowledge into practice and at the long-run play their role in preventing or decreasing antibiotic resistance correctly when they go out to the society.

\section{Contribution of the findings}

The knowledge of antibiotic resistance and appropriate attitudes towards the usage of these antibiotics by these particular group students can assist in the rational use of these drugs and can also further help decrease the rate of emergence of antibiotic resistance in the students' societies because it is hoped that these students will have a direct or indirect role to play in the health sector in the future and even before that the students in medical line are regarded as source of health-care related advice by family and friends, with respect to these role played by these students in their societies, their level of knowledge on antibiotic resistance and their attitude of antibiotic usage can have a huge impact on the population and also have an influence on the arising issue of antibiotic resistance. Knowing the level of the students' knowledge and their attitude can help the policymakers or any other body in charge to have an idea on how to tackle the issue of antibiotic resistance awareness and also enlightenment on good antibiotic practices at both students' level and the society at large.

\section{Future research}

A survey should be carried out among the students in healthrelated fields to determine the knowledge, attitude and practice on antibiotic resistance and the data obtained should be compared to that of students of non-health related fields or the general public. In order to know the most appropriate starting point when we want to devise solution to the continuous increase in the rate at which resistance to antibiotics is being developed.

\section{References}

1. World Health Statistics (2016) Monitoring health for the SDGs sustainable development goals: World Health Organization 2016

2. Mendelson M, Matsoso MP (2015) The World Health Organization global action plan for antimicrobial resistance. South Afr Med J 105: 325.

3. Abay S, Amelo W (2010) Assessment of self-medication practices among medical, pharmacy, and health science students in Gondar University, Ethiopia. J Young Pharm 2: 306 .

4. Al Barakh N, Algain S, Al Barrak A, Al Mazrooa S, Alfaleh S, et al. (2016) The assessment of Knowledge, attitude and practice of antibiotics usage among Saudi female students in Princess Nourah University (PNU). J Pharma Care Health Sys 2: 1.

5. Suaifan GA, Shehadeh M, Darwish DA, Al-Ije H, Yousef A-MM, et al. (2012) A cross-sectional study on knowledge, attitude and behavior related to antibiotic use and resistance among medical and non-medical university students in Jordan. Afr J Pharm Pharmacol 6: 763-770.

6. Haque M, Rahman NIA, Zulkifli Z, Ismail S (2016) Antibiotic prescribing and resistance: knowledge level of medical students of clinical years of University Sultan Zainal Abidin, Malaysia. Ther Clin Risk Manag 12: 413. [Crossref]

7. Awad AI, Eltayeb IB (2007) Self-medication practices with antibiotics and antimalarials among Sudanese undergraduate university students. Ann Pharmacother 41: 1249-1255. [Crossref]

8. Abass AM, Ahmed ME, Ibrahim IG, Yahia S (2016) Bacterial Resistance to Antibiotics: Current Situation in Sudan. J Adv Microbiol 6: 1-7.

9. Abbo LM, Cosgrove SE, Pottinger PS, Pereyra M, Sinkowitz-Cochran R, et al. (2013) Medical students' perceptions and knowledge about antimicrobial stewardship: how are we educating our future prescribers? Clin Infect Dis 57: 631-638. [Crossref]

Copyright: (C2019 Sunusi LS. This is an open-access article distributed under the terms of the Creative Commons Attribution License, which permits unrestricted use, distribution, and reproduction in any medium, provided the original author and source are credited. 